\title{
Students' Attitudes about Self-Assessment: A Neglected Aspect in the Algerian EFL Classrooms
}

\author{
Nawal Kadri ${ }^{1, *}$, Hamid Amziane ${ }^{2}$ \\ ${ }^{1}$ Department of English, University Abderrahmane Mira, Bejaia, Bejaia Province, Algeria. \\ ${ }^{2}$ Department of English, University Mouloud Mammeri, Tizi Ouzou, Tizi ouzou Province, Algeria.
}

\begin{abstract}
How to cite this paper: Nawal Kadri, Hamid Amziane. (2021). Students' Attitudes about Self-Assessment: A Neglected Aspect in the Algerian EFL Classrooms. The Educational Review, USA, 5(8), 275-286.
\end{abstract}

DOI: 10.26855/er.2021.08.004

Received: July 10, 2021

Accepted: August 6, 2021

Published: August 23, 2021

Corresponding author: Nawal Kadri, Department of English, University of Bejaia, Bejaia, Bejaia Province, Algeria.

Email: nawal.k.09@hotmail.fr

\begin{abstract}
Students' ability to assess their own learning and determine their progress has become the focus of most educational research recently. As far as English foreign language (EFL) learning is concerned, much attention is increasingly given to self-assessment as it represents a key factor for successful learning. Self-assessment embodies thinking and reflection skills that are at the heart of the learning process. Yet, successful implementation of this formative process depends on teachers' and students' perceptions of their roles in the assessment process. The purposes of this study are twofold. First, the researchers seek to explore students' attitudes towards self-assessment and their needs to better understand how self-assessment is approached in the Algerian milieu. The second goal is to match between these perceptions and needs in order to help teachers integrate self-assessment into their instructional plans to improve students' learning and encourage self-regulation which is the ultimate goal of the Higher Education reform. This investigation which targets students' written competence limits itself to a sample of sixty eight EFL undergraduate students at the University of Bejaia who completed a self-administered questionnaire. The results of a series of statistical and content analyses guided the researchers to discuss some implications for the integration of self-assessment into EFL classrooms.
\end{abstract}

\section{Keywords}

EFL learning, formative assessment, self-assessment, students’ attitudes, students' needs

\section{Introduction}

Writing plays a significant role in EFL learning as it develops not only linguistic knowledge about the foreign language, but also students' critical thinking and creativity. Assessment of EFL writing is an integral part of the teaching and learning process; it helps to determine whether the goals of education are being met or not. In 2004, the Algerian Ministry of Higher Education started to launch a reform by implementing the Licence, Master and Doctorate (LMD) system into some of the Algerian universities. This reform involves both instruction and assessment. As far as the assessment aspect of this reform is concerned, attention has been directed towards on-going type of evaluation as an alternative to the traditional forms of testing mostly used. Driven by the ultimate need to focus classrooms on student-centeredness to promote their autonomy, the LMD reform targets alternative assessment as a part of the educational process. Forms of alternative assessment such as projects, portfolios, self-assessment and peer assessment have been demonstrated to have a significant role in developing students' learning skills (Black \& Wiliam, 1998; Reeves, 2000). One appealing form of alternative assessment focused on in our study is self-assessment which has been increasingly used in EFL classrooms to develop students' writing com- 
petence (Andrade \& Boulay, 2003; Andrade, 2010).

\section{Statement of the Problem}

As already mentioned, the evaluation reform launched in 2004 in the Algerian Universities brought new insights about teachers' roles, students' tasks and assessment forms. Because assessment affects significantly students' learning experience, there is a need to involve students' in the assessment process and encourage them to manage their progress in order to identify their strengths and weaknesses. Yet, students' actions and reactions towards this new assessment approach depend highly on their attitudes and beliefs about assessment in general and their roles as well as willingness to engage in constant review of their writing performance. Given these points, the central problem of this research is to explore students' beliefs and attitudes towards self-assessment and investigate their needs. This has aim of getting a better understanding of how self-assessment is approached in the Algerian milieu and matching between these perceptions and needs in order to help teachers incorporate self-assessment into their instructional plans.

Based on this, some research questions need to be answered:

1) Is self-assessment integrated into EFL writing instruction at the University of Bejaia?

2) How do EFL Algerian students view self-assessment of EFL writing?

3) What are the challenges that affect students' attitudes towards self-assessment?

4) What are these students' needs and expectations?

\section{Review of Literature}

\subsection{Self-assessment as a form of alternative assessment}

Traditional assessment or testing, regardless of its purpose, has long been a dominant type of assessment in EFL classrooms and may still be. Traditional assessment can be defined as single occasions and timed exercises through which students' performance is measured. It is primarily carried out to score students' performance and accredit their learning (Andrade \& Cizek, 2010). Critics, however, have recently raised serious concerns about the usefulness of various kinds of tests as the primary measure of students' achievement. In this vein, researchers have pointed out the failure of these tests to capture the multi-dimensional aspects of what students have learned (Mathies, 2000; Crooks, 1988; Wiggins \& McTighe, 2007; Jonsson \& Svingby, 2007; Darling-Hammond \& Adamson, 2010). Such summative tools also fail to account for students' needs and expectations. Because it represents a one way teacher-student assessment procedure, this type of assessment puts solely teachers in the position to make decisions.

To overcome these limitations, interest has been moved away from traditional to more authentic types of assessment such as alternative assessment tools which are named portfolios, projects, demonstrations, conferences, rubrics and reflection journals. These forms of assessment, which relate classroom instruction to the real-world experience of the learners, have been demonstrated to be formative and constructive as they engage students in the assessment process by increasing their responsibility for their writing and by boosting their motivation to learn (McMillan \& Hearn, 2008; Rolheiser \& Ross, 2001; Panadero \& Alonso-Tapia, 2013). The benefit for the teacher is also to be met in so far as he/she changes his/her expertise by adopting an interactive method with the student by observing, collecting, describing and interpreting data for the purpose of informing instruction, adjusting teaching and improving learning. When one considers the main characteristics of foreign language writing, alternative assessment seems to be more appropriate and beneficial; yet this type of assessment carries some concerns in terms of practicality, subjectivity, provision of feedback and coaching. If appropriately applied, alternative assessment can increase achievement by developing students' full range of abilities.

One form of alternative assessment stressed in the present study is self-assessment which involves students in the assessment process. Self-assessment can be defined as a continuous personalised process wherein students constantly review and judge the quality of their works against pre-defined criteria under the teacher's supervision. Angelo and Cross (1993) describe it as on-going, learner-centered, teacher-directed, mutually beneficial and content-specific.

However, this type of formative assessment is a complex process that requires conditions to be established. The first principle of self-assessment is the active engagement of students in the assessment process. Students take charge of their writing by constantly reviewing and analysing their own performance. Nevertheless, it should be highlighted here that self-assessment occurs only when students are guided and supported by the teacher (Gardner, 2000). Self-assessment is not about leaving students on their own, but on providing opportunities for them to make adequate choices. Another important condition in students' effective assessment of their own performance is the access to the assessment criteria. In this respect, many researchers (Nicol \& Macfarlane-Dick, 2006; Andrade, 2010) stress the need to make criteria explicit enough so as students understand clearly against which standards they are going to compare 
their work. In addition, these criteria should ensure accuracy and objectivity in their judgments.

\subsection{Self-assessment Benefits}

Researchers have discussed several advantages of self-assessment and provided evidence on the positive effects this on-going process has on students' writing skill (Andrade \& Bouley, 2003; Andrade \& Valtheva, 2009). Self-assessment is considered beneficial for both personal and academic development through the process of reflection and critical analysis of one's personal performance. That is, self-assessment serves both learning and assessment purposes; students become constructors of their own learning and managers of their own progress. Self-assessment offers the possibility to take charge of their own learning and make decisions (Muñoz \& Alvarez, 2007, p. 13). It also assists students in identifying gaps between their current and desired states through identification of strengths and weaknesses. In this case, self-assessment is said to provide cumulative information about one's progress (McMullan, 2006, p. 333). Regarding the affective side, self-assessment has been demonstrated to boost students' motivation and internal control (Blue, 1994; Elliot \& Higgins, 2005; McMillan \& Hearn, 2008, p. 43). Self-assessment is also considered as an effective pedagogical tool that improves instruction and enhances the collaborative relationship between teachers and students. In this vein, Richards (1996) views self-assessment as a continuous record of students' language development which facilitates planning for instruction. Consequently, it helps teachers to respond more precisely to students' needs (Ross, Rolheiser, \& Hogaboam-Gray, 1999; Russell \& Airasian, 2012).

\subsection{Students’ Attitudes}

It is clear that students' beliefs and attitudes influence their actions and reactions to a great extent. In this regard, Brown and Harris (2012, pp. 46-47) claim : "what students think about the nature of assessment, their roles, and the purposes of the assessment is likely to affect how they respond to and participate in these practices ...”. Yet, we can notice the relatively limited body of research on students' attitudes about self-assessment, mainly in Algeria.

It is worth noting, however, that self-assessment can be perceived differently by students. Some develop positive attitudes towards self-assessment while others feel reluctant to engage in this process. Thanks to their reasonable conceptualisations of learning, the former view self-assessment as a useful learning tool. Struyven, Dochy and Janssens (2002) reviewed several studies on students' self-assessment and found that self-assessment was perceived as challenging, helpful and beneficial insofar as students are stimulated to reflect and demonstrate their skills and abilities. This is also what Ranrahan and Isaacs (2001), Andrade and Du (2005) and Chelli (2013) reported in their studies. Similarly, Muñoz and Alvarez (2007) concluded in their study on Colombian students that students perceived self-assessment as helpful and useful because it helped them improve their learning through recognition of their own knowledge and abilities.

On the other hand, the latter students may regard self-assessment negatively. Supporting this, Liang (2006) reported students to perceive self-assessment as irrelevant and inappropriate. In another study, McMullan (2006) concluded that students in the United Kingdom find self-assessment ineffective and time consuming, causing them a big deal of anxiety. Similarly, Brown and Harris (2012) noticed students' negativity towards the use of self-assessment in many studies.

In fact, students' negative conceptions of self-assessment are linked to many factors as listed below:

- Lack of awareness,

- Students' conceptions of assessment as the teacher's responsibility (Ross, 2006),

- Students' unfamiliarity with the process and inexperience (blue, 1994; Darling-Hammond \& Adamson, 2010),

- Lack of autonomy (Gallagher, 2001),

- Lack of motivation (Gardner, 2000; Gallagher, 2001),

- Anxiety (MucMullan, 2006),

- Classroom and environmental constraints (Brown \& Harris, 2012).

The reported studies revealed interesting but quite opposite results. Understanding students' attitudes towards self-assessment and the reasons behind such attitudes represents a key factor for improving self-assessment. Educators should focus on changing these factors in order to improve the use of self-assessment.

\section{Methodology}

\subsection{Participants}

The present investigation was carried out in Bejaia University, Algeria; 68 students participated in this study. The respondents were 60 females and 8 males ranging from 20 to 27 years old. All the participants were third year English students at the University of Bejaia. 


\subsection{Research Instrument and Procedures}

In order to investigate students' attitudes about self-assessment at the University of Bejaia, the researchers have opted for the use of a questionnaire which was administered to the 68 participants. The questionnaire consists of four sections designed according to the aims of the study. The first section is devoted to the collection of personal information about the participants (age and gender). The second section concerns classroom practice. Section three focuses on students' attitudes towards the usefulness of self-assessment and their willingness to use it. The last section is devoted to students' needs and expectations in EFL writing classes. The questionnaire consists of close-ended and open-ended questions. A copy is shown in Appendix A.

\subsection{Data Analysis}

The questionnaire yielded both quantitative and qualitative data. Results obtained from the close-ended questions were analysed quantitatively using the statistical package for social sciences (SPSS) version 18 based on percentages. To get qualitative data, the researchers opted for content analysis in which students' answers to the open-ended questions are grouped (thematic analysis). In addition to statistics, the qualitative analysis permitted us to get insight into students' beliefs, perceptions as well as expectations.

\section{Results}

\subsection{Classroom Practice}

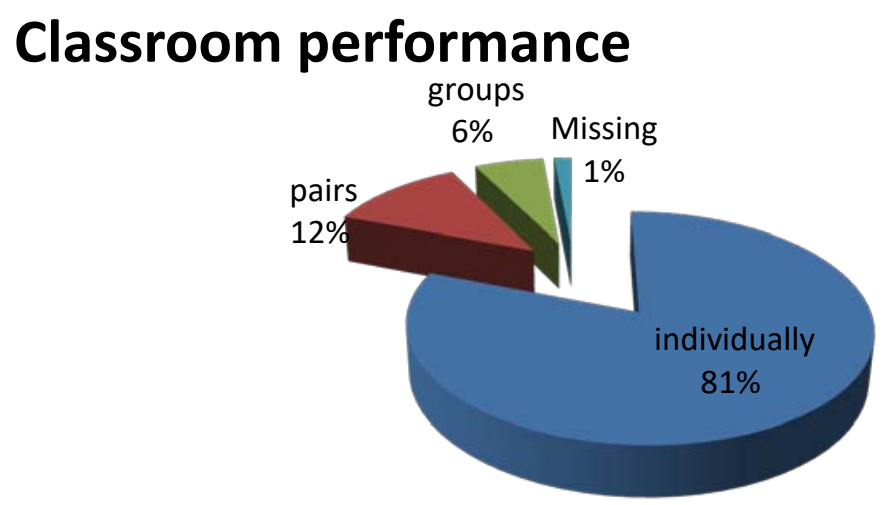

Figure 1. Students' answers to Question 1 regarding how they are assigned to write in the classroom.

As Figure 1 shows, students' answers to the first question revealed that they are generally assigned to write individually in the classroom as reported by $81 \%$ of the participants. Only few students reported working in pairs or groups.

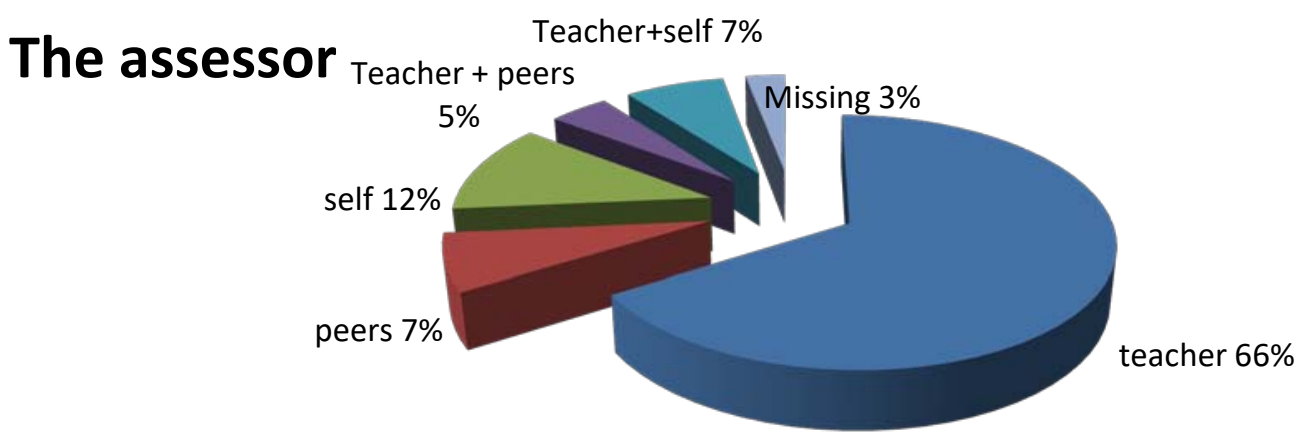

Figure 2. Students’ answers to Question 2 regarding who assesses their writing.

As far as the process of assessment is concerned, most of the participants (66\%) indicated that their written compositions are assessed by their teachers (Figure 2). This means that teacher-assessment is the dominant type of assessment used in EFL writing classrooms in Bejaia University. 


\section{Assessment techniques}

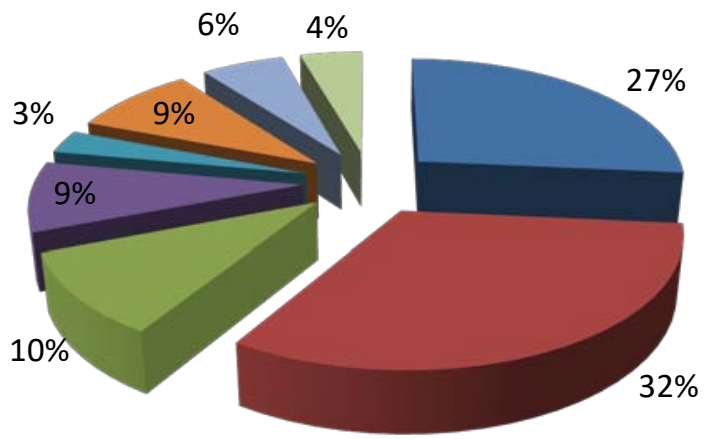

\author{
grades \\ Written comments \\ codes \\ - Mention the level \\ grades\& comments \\ comments \& codes \\ different techniques \\ Missing
}

Figure 3. Students' answers to Question 3 concerning the assessment techniques their teachers use to assess their writing.

When assessing students' writings, some teachers, as indicated by 32\% of participants, write comments at the end of students' papers, whereas others (27\% of answers) are still relying on summative forms of assessment by providing grades. Only $10 \%$ of students reported that their teachers use writing codes to pinpoint their errors and few teachers use different techniques combined together as reported by some students 6\% (Figure 3).

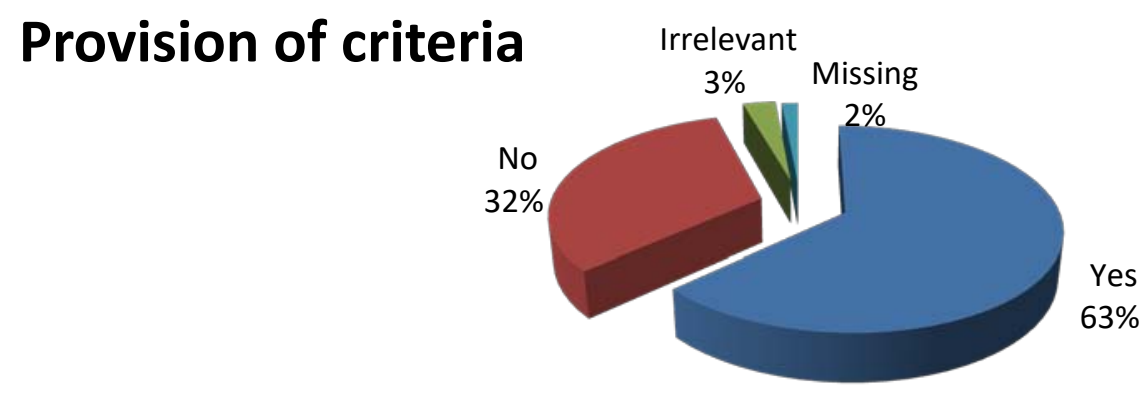

Figure 4. Students' answers to Question 4 about discussing assessment criteria in the classroom.

The statistics presented in Figure 4 reveals that most of the students (63\%) have access to assessment criteria. However, the question that rises is whether students do really understand these criteria of assessment and apply them appropriately. The answer to this question needs a qualitative analysis of students' written productions that is beyond the scope of this research.

\subsection{Attitudes about Self-Assessment}

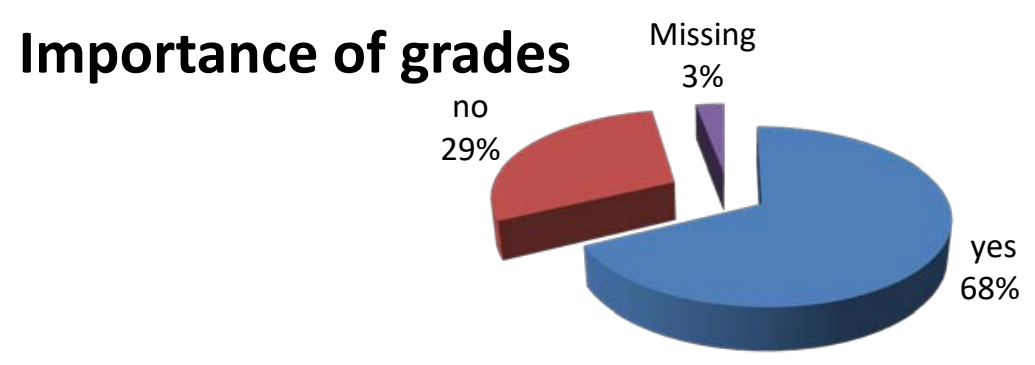

Figure 5. Students' answers to Question 5 regarding their attitudes towards the role of scores in EFL writing achievement.

The statistics presented in Figure 5 reveal that the majority of students (68\%) believe that scores are important factors that determine their level of achievement. This conceptualisation may result from teachers' classroom practices which 
give much importance to scores.

\section{Willingness to use SA}

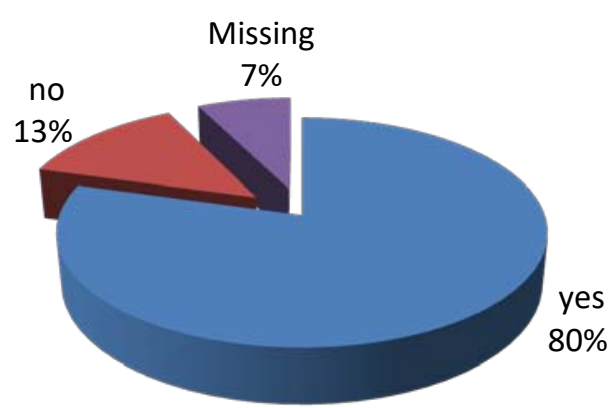

Figure 6. Students' answers to question 6 asking whether they think their teachers should give them responsibility to self-assess their written works.

From Figure 6, we can estimate that the vast majority of students (80\%) are willing to take part in the assessment process. This is actually a good sign of students' motivation to engage in self-assessment in EFL writing classrooms.

\section{Perception of importance}

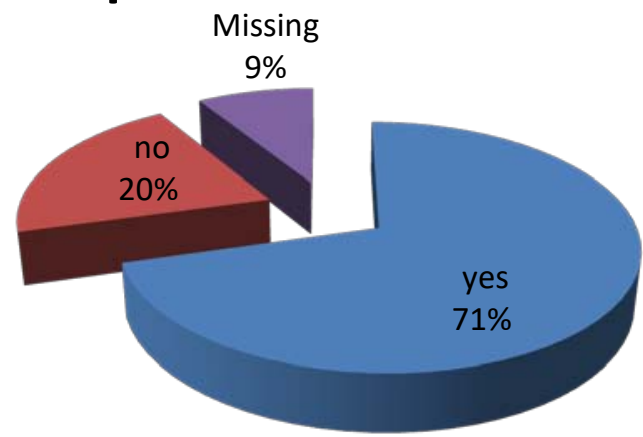

Figure 7. Students' answers to Question 7 regarding their beliefs about the potential benefits of self-assessment on their writing if they become familiar with the self-assessment process.

Students' answers reported in Figure 7 reveal students' positive attitudes about self-assessment as $71 \%$ believe that self-assessment is beneficial for their writing. To reinforce students' answers, we elicited explanations from the participants to understand further their viewpoints. Some of their arguments are quoted below:

Student $1{ }^{1}$ : "I could try to find and detect what is wrong..."

Student 2: "It is an effort which is fruitful at the end of each writing process since it is a kind of training and at the same time it develops our ability to find the mistakes and not to repeat them again"

Student 3: "Because I'm more likely to remember a mistake that I've corrected myself than one that my teacher corrected."

Student 4: "If we do it together [the students and the teacher], I can evaluate and improve my writing."

Student 5: "It will lead me to think deeply, so I will not do them [mistakes] again."

Student 6: "It makes me concentrate more to what I'm doing and pay attention to my writing."

Student 7: "I will feel responsible of each word I wrote, and make more efforts to avoid doing the same mistakes, I feel like a teacher when he corrects students' papers."

From the above stated arguments, it is clear that these students recognise their role in the learning process and are aware of the importance of self-assessment. Yet, a minority of students reject the idea of self-assessment and is unwil-

1 The enumeration of the students follows the same chronological order for all the questions $(1,2,3, \ldots)$, so the same number does not mean the same student. 
ling to use it. These students provided reasons for their negative attitudes as reported below:

Student 1: "because the only who can define or find your mistakes is the teacher, as a student, you won't manage to find your mistakes."

Student 2: "I am doing a duty that is not mine."

Student 3: "I haven't a high level to improve my writing alone."

It is clear from students' statements that these students still think of assessment as the teacher's mere responsibility and they also feel incompetent at doing so due to their limited writing proficiency.

Students' answers to question seven are reinforced by question eight in which they were asked about their feelings about self-assessment as a learning experience. Students' answers to both questions have been summarised in Table 1 below.

Table 1. Students' conceptions of and feelings about self-assessment

\begin{tabular}{ll}
\hline Positive attitudes and feelings & Negative attitudes and feelings \\
\hline & \\
Increased responsibility & Inability to assess my work alone \\
Enhanced confidence & Teacher's responsibility \\
Feeling of trust & Anxiety and stress \\
Improved performance & Unfamiliarity/ inexperience \\
Enjoyable experience & No perceived benefits \\
Self- detection of mistakes & Feelings of shame due to mistakes \\
Self-learning & Preference towards group work \\
Paying attention & Subjectivity \\
Positiveness & \\
\hline
\end{tabular}

As we can see in the table above, our participants' feelings and attitudes go hand in hand with what we have explained in the review of the pertinent literature about attitudes towards self-assessment. Students who value self-assessment believe in its potential to develop their writing, whereas those who misunderstand this process develop negative attitudes about it.

\title{
5.3 Students’ Needs and Expectations
}

Understanding students' needs represent a key element for the development of education and the success of any educational program. The thematic analysis of students' answers to the question about their needs and expectations revealed important conceptualisations. Students' answers are summarised in Table 2 and some of the common responses were quoted below in their original version.

Table 2. Students' Needs and Expectations

\author{
Direct instruction and illustrations \\ Assistance with strategy use \\ Support and guidance \\ Boost our motivation \\ Feedback \\ Give advice \\ Provide opportunities for practice
}

Student 1: "I need the teacher simplifies me the method how to write and makes of writing something easy to practice with confidence."

Student 2: "I need instructions and techniques of a good writing."

Student 3: "To improve myself, I need from the teacher just to guide me in the techniques of writing and useful tips that will help me write in a good way in any given topic and any type of writing."

Student 4: "correct my mistakes friendly, give remarks that help improving my style, try to teach me writing methods ...”

Student 5: "Giving and providing us with more tasks concerning writing."

Student 6: "practice and practice."

Student 7: "Teachers should give us to write frequently and correct our mistakes together." 


\section{Student 8: “correct our mistakes.”}

The participants revealed different needs and expectations from their teacher, but we have reported the most common needs as shown in Table 2. Instruction, support, feedback and practice seem to be what students need mostly in their EFL writing classes.

\section{Discussion}

The interpretation of both the quantitative and the qualitative data obtained from the questionnaire allowed the researchers to get insight into the teaching and learning of EFL writing at the University of Bejaia, Algeria. Students' learning experiences demonstrate that EFL teachers are still relying on traditional methods of instruction (product approach) and assessment (summative) in EFL writing classrooms. This can be generalised to the three levels of B.A. as our participants reported their experiences during the three years of study at the University of Bejaia. It is worth mentioning here that no student referred to alternative assessment techniques like checklists, rubrics, portfolios and so on. This means that teacher-assessment is the common form of assessment used. When looking at students' needs and expectations, it appears that the assessment methods and techniques adopted by EFL teachers in writing classrooms have little impact on the development of students' writing competence. The students expressed their ultimate need for instruction, feedback and practice. They pointed out the deficiency of teachers' instructional methods and they further claimed that they do not write regularly and they lack constructive feedback that would permit them to identify their strengths and weaknesses. This is quite obvious because traditional approaches to assessment do not engage students in the assessment process, they do not record their continuous progress and most importantly they do not provide opportunities for revision and improvement.

As far as students' attitudes about self-assessment are concerned, our findings go hand in hand with other research findings (Muñoz \& Alvarez, 2007; Chelli, 2009; Tshabalala \& Ndimande, 2016). The vast majority of the participants of this study have positive attitudes about self-assessment and believe in its usefulness and effectiveness in developing their writing competence. In addition to their positive attitudes, the students expressed their willingness to use self-assessment in their EFL writing classes in order to improve their performance. Yet, similar to what Ross (2006) explained, the students who are unwilling to self-assess their writing think that assessment is the teacher's mere responsibility. This reluctance towards the process of self-assessment can also be justified by the students' lack of confidence or false conceptions about self-assessment. Many students think that self-assessment is about leaving the student alone and this is a common misconception among students and even teachers. Besides, students' inexperience with the use of self-assessment may cause a great deal of anxiety and fear among students which may in turn decrease their motivation towards this form of assessment. These negative attitudes and reluctance represent a real challenge for educators.

Drawing on the results obtained, this article suggests consideration of the value of self-assessment and stresses the need to integrate this formative process into EFL writing instruction by focusing on its potential advantages. Students need to be engaged in constant review and analysis of their performance in order to learn to make their own decisions and be less dependent on their teachers. To reach this end, we have developed some suggestions for both EFL teachers and students. These suggestions are listed below:

- Encourage practice of the writing process,

- Change beliefs regarding the role of the students and the teacher in the educational process

- Raise awareness among students on the benefits of self-assessment and highlight teachers' role in guiding and supporting students in conducting self-assessment and in how to use the instruments.

- Train and provide support in developing the skills necessary for accurate self-assessment: teachers should understand how to use different techniques like rubrics, checklists, conferences and portfolios to encourage students to review their progress

- Adopt models of self-assessment suggested in the literature

- Practice: teachers should create opportunities for self-assessment to occur

- Feedback: teachers should help students understand the meaning of the self-assessment results by providing constant constructive feedback

These suggestions represent vital steps towards the implementation of self-assessment in any EFL classroom.

\section{Conclusion}

The purpose of the present study is to develop our understanding of Algerian students' beliefs and conceptions of the benefits and problematic aspects of self-assessment in EFL writing classrooms in higher education. The results obtained 
both support and extend previous research and give a more detailed picture of the Algerian students' attitudes about self-assessment. We can conclude that most of the students develop positive attitudes towards self-assessment and recognise its significant role in developing their writing competence through the process of self-discovery. Yet, the process is not integrated into EFL writing instruction in Bejaia University. If EFL students and EFL teachers become aware of the benefits of self-assessment, and if they experience the potential of this on-going constructive process, students will become effective self-regulators and better equipped to make their own decisions on how to improve their writing and certainly be less dependent on the teacher. Despite the interesting results obtained, some research limitations may prevent the overgeneralisation of our results. It is of paramount importance to point out that the current study was conducted within a limited scope in terms of the number of participants (68), on one hand and the restricted setting to one Algerian University, on the other hand. Hence, it might be replicated by including a large number of students from different universities. It is also possible to replicate the study using other research methods like interviews and conducting experimental studies on self-assessment. Further research is also needed on the role of the educational context in promoting self-assessment. To end with, we would like to highlight the urgent need for university teacher training and development in line with this pedagogical option.

\section{References}

Andrade, H. and Cizek, G. J. (Eds.). (2010). Handbook of Formative Assessment. Routledge.

Andrade, H. and Valtcheva, A. (2009). Promoting Learning and Achievement through Self-Assessment. Theory into Practice, 48(1), 12-19. DOI: $10.1080 / 00405840802577544$.

Andrade, H. G. and Boulay, B. A. (2003). Role of Rubric-Referenced Self-Assessment in Learning to Write. The Journal of Educational Research, 97(1), 21-34. Retrieved from http://www.jstor.org/stable/27542460.

Andrade, H. L. (2010). Students as the Definitive Source of Formative Assessment: Academic Self-Assessment and the Self-Regulation of Learning. NERA conference Proceedings 2010 paper 25.

Andrade, H. L. and Du, Y. (2005). Student Perspectives on Rubric-referenced Assessment. Practical Assessment Research \& Evaluation, 10(3), 1-11.

Angelo, T. A. and Cross, K. P. (1993). Classroom assessment techniques: A handbook for college teachers. San Francisco: Jossey-Bas.

Black, P. and Wiliam, D. (1998). Inside the black box: Raising standards through classroom assessment. Granada Learning. Phi Delta Kappan, 139-148

Blue, G. M. (1994). Self-Assessment of Foreign Language Skills: Does It Work? CLE Working Papers, (3), 18-35.

Brown, G. and Harris, L. (2012). Student conceptions of assessment by level of schooling: Further evidence for ecological rationality in belief systems. Australian Journal of Educational \& Developmental Psychology, 12, 46-59.

Chelli, S. (2009). The Competency Based Approach \& the LMD System in Pedagogical Days at the University of Biskra. Retrieved on July $20^{\text {th }}$, 2015 from http://dspace.univ-biskra.dz:8080/jspui/bitstream/123456789/3570/1/cba\%20\%26\%20lmd.pdf.

Crooks, T. J. (1988). The impact of classroom evaluation practices on students. Review of educational research, 58(4), $438-481$.

Darling-Hammond, L. and Adamson, F. (2010). Beyond basic skills: The role of performance assessment in achieving 21st century standards of learning. Stanford Center for Opportunity Pollcy in Education.

Elliott, N. and Higgins, A. (2005). Self and Peer assessment-Does it Make a Difference to Student Group Work? Nurse Education in Practice, 5, 40-48. doi:10.1016/j.nepr.2004.03.004.

Gallagher, P. (2001). An evaluation of a standards based portfolio. Nurse Education Today, 21(3), 197-200.

Gardner, D. (2000). Self-assessment for Autonomous Language Learners. Links \& Letters, 7, 49-60.

Hanrahan, S. J. and Isaacs, G. (2001). Assessing Self- and Peer-assessment: the Students' Views. Higher Education Research \& Development, 20(1), 53-70.

Jonsson, A. and Svingby, G. (2007). The use of scoring rubrics: Reliability, validity and educational consequences. Educational research review, 2(2), 130-144.

Liang, J. (2006). Overview of self-assessment in the second language writing classroom. In TESOL Convention, Tampa, Florida. Available at: http://secondlanguagewriting.com/explorations/Archives/2006/Apr/TESOL2006Self-assessment.html.

McMillan, J. H. and Hearn, J. (2008). Student self-assessment: The key to stronger student motivation and higher achievement. Educational Horizons, 87(1), 40-49.

McMullan, M. (2006). Students' perceptions on the use of portfolios in pre-registration nursing education: A questionnaire survey. International Journal of Nursing Studies, 43, 333-343. 
Muñoz, A. and Alvarez, M. E. (2007). Students' Objectivity and Perception of Self Assessment in an EFL Classroom. The Journal of Asia TEFL, 4(2), 1-25.

Nicol, D. J. and Macfarlane-Dick, D. (2006). Formative Assessment and self-regulated Learning: a Model and Seven Principles of Good Feedback Practice. Studies in Higher Education, 31(2), 199-218, DOI: 10.1080/03075070600572090.

Panadero, E. and Alonso-Tapia, J. (2013). Self-assessment: Theoretical and Practical Connotations. When It Happens, How It is Acquired, and What to Do to Develop It in Our Students. Educational Journal of Research in Educational Psychology, 11(2), 551-576.

Reeves, T. C. (2000). Alternative Assessment Approaches for Online Learning Environments in Higher Education. Journal of Educational Computing Research, 23(1), 101-111.

Richards, J. C. (Ed.) (1996). Classroom-Based Evaluation in Second Language Education. Cambridge University Press.

Rolheiser, C. and Ross, J. A. (2001). Student self-evaluation: What research says and what practice shows. Plain Talk about Kids, 43, 57.

Ross, J. A. (2006). The Reliability, Validity, and Utility of Self-Assessment. Practical Assessment Research \& Evaluation, 11(10), 1-13.

Ross, J. A., Rolheiser, C., and Hogaboam-Gray, A. (1999). Effect of self-evaluation on narrative writing. Assessing Writing, 6(1), 107-132.

Russell, M. K. and Airasian, P. W. (2012). Classroom assessment: concepts and applications (7 ${ }^{\text {th }}$ ed.). New York: Mc Graw Hill.

Struyven, K., Dochy, F., and Janssens, S. (2005). Students' perceptions about evaluation and assessment in higher education: a review. Assessment \& Evaluation in Higher Education, 30(4), 325-341. DOI: 10.1080/02602930500099102.

Tshabalala, N. G. and Ndimande, T. A. (2016). The Perceptions of Students and Staff towards Portfolio Assessments: The Case of Mangosuthu Technikon in Kwa Zulu-Natal Province South Africa. Mediterranean Journal of Social Sciences, 7(3), 319-330. Doi:10.5901/mjss.2016.v7n3p319.

Wiggins, G. P. and McTighe, J. (2007). Schooling by design: Mission, action, and achievement. ASCD. 


\section{Appendix: Students’ Questionnaire}

\section{University Abderrahmane Mira, Bejaia \\ Questionnaire: Students' Attitudes and experiences}

Dear students,

In this research work, the researchers are investigating students' beliefs and opinions about classroom assessment. We would like you to answer these questions anonymously and honestly. Your help is a contribution to this work.

Background Information: Could you please indicate:

- Your Age:

- Your gender.

\section{Classroom Practice/Experience}

1. In the classroom, how are you assigned to write?
a. individually
b. in pairs
c. in groups

2. Who assesses (judges) your writing?
a. the teacher
b. your classmates
c. yourself

3. What techniques does your teacher use to assess your writing?
a. attributing a grade
c. writing comments at the end of the paper
d. using correction codes
e. telling you about your level (e.g.,good, average, poor).
f. Another answer:

4. Does your teacher tell you in advance on which basis your writing will be judged/ assessed (assessment criteria)?
a. yes
b. no
c. Another answer:

\section{Students’ Attitudes}

5. Do you think that scores are true indicator of achievement in EFL writing?
a. Yes
b. No
How?

6. Do you think that your teacher should give you responsibility to correct your mistakes by yourself first?
a. yes
b. no

7. Do you think you will improve your writing if you have the habit to assess (check and correct) your written texts by yourself before handing them to the teacher?
a. yes
b. no 
How?

8. How would you feel if you are asked to assess your work by yourself?

\section{Students' Needs and Expectations}

9. What do you need from your teacher to help you improve your writing?

Thank you for your contribution 